\title{
OPEN Impact of temporal variability of radon concentration in workplaces on the actual radon exposure during working hours
}

\author{
G. Venoso ${ }^{1 凶}$, A. lacoponi ${ }^{2}$, G. Pratesi ${ }^{2}$, M. Guazzini' ${ }^{2}$, L. Boccini ${ }^{2}$, E. Corbani $^{2}$, S. Bucci $^{2}$, \\ F. Leonardi ${ }^{3}$, R. Trevisi ${ }^{3}$, M. Ampollini ${ }^{1}$, S. Antignani ${ }^{1}$, M. Caprio ${ }^{1}$, C. Carpentieri ${ }^{1}$, \\ C. Di Carlo ${ }^{1} \&$ F. Bochicchio ${ }^{1}$
}

For workplaces where significant diurnal variations in radon concentrations are likely, measurements to evaluate average radon concentration during working hours could be useful for planning an optimized protection of workers according to the 2013/59/Euratom Directive. However, very few studies on this subject, generally limited to periods of few weeks, have been published. Therefore, a study has been conducted to evaluate the actual long-term radon exposure during working hours for a sample of 33 workplaces of four different types (postal offices, shops, restaurants, municipal offices), mainly located at the ground floor, and with expected considerable air exchange rate occurring during working hours due to frequent entrance/exit of persons or mechanical ventilation. The results show that the difference between the average radon level during working hours and that one during the whole day is about $20 \%$ on average and ranges from 0 to $50 \%$. These observed differences, generally smaller compared with those found in other similar studies, are nearly the same if the analysis is restricted to workplaces with annual radon level higher than $300 \mathrm{~Bq} \mathrm{~m}^{-3}$, and therefore natural or mechanical ventilation normally present during working hours of the monitored workplaces cannot be considered an effective mitigation measure. However, the costs and time-response characteristics of the active monitors, as those used for the present study, will probably allow using more frequently a similar measurement strategy in workplaces.

The new international regulations and recommendations ${ }^{1,2}$ have introduced the new concept of reference level (RL). They require that, for workplaces resulted to have an annual average radon level higher than RL, action has to be taken in agreement with the optimization principle to reduce radon exposure. Besides mitigation measures, the optimization actions may also include measurements to investigate the activity concentration during working hours, if appropriate ${ }^{3}$. Indeed, in some workplaces may occur that radon concentrations averaged during the working hours were much lower (well below a RL of $300 \mathrm{~Bq} \mathrm{~m}^{-3}$ ) than those averaged over the whole day, in some cases ${ }^{4,5}$ also higher than $1000 \mathrm{~Bq} \mathrm{~m}^{-3}$. It is the case of some workplaces or schools having mechanical ventilation systems active during the working hours only, being turned off during night-time and the weekends.

In some countries, such as Norway ${ }^{6}, \mathrm{Canada}^{7}$ and Finland ${ }^{8}$, for these types of workplaces, the following monitoring strategy is adopted to demonstrate compliance with reference levels: if the results of long-term radon concentration measurements carried out with passive devices were higher than the national reference level, continuous monitoring of at least one week is recommended or required. However, in literature few experimental studies exist investigating the difference between the average radon level during working hours and the yearly averaged concentration. Moreover, to the authors' knowledge, no extensive study has been performed over periods longer than few weeks.

In the framework of a project promoted by INAIL, four types of workplaces have been identified among those for which it is likely to find significant diurnal variations in radon concentrations. In a sample of these workplaces,

\footnotetext{
${ }^{1}$ National Center for Radiation Protection and Computational Physics (Italian National Institute of Health), Viale Regina Elena, 299 Rome, Italy. ${ }^{2}$ Florence Section, Regional Agency for Environmental Protection in Tuscany (ARPAT), Via Ponte alle Mosse 211, 50144 Florence, Italy. ${ }^{3}$ Italian National Institute for Insurance against Accidents at Work (INAIL)-DiMEILA, Via Fontana Candida, 1 Monte Porzio Catone, Rome, RM, Italy. ${ }^{\square}$ email: gennaro.venoso@iss.it
} 


\begin{tabular}{|l|l|l|}
\hline Type of workplaces & No. of buildings & No. of rooms \\
\hline Postal offices & 5 & 8 \\
\hline Shops & 5 & 5 \\
\hline Restaurants & 6 & 10 \\
\hline Municipal offices & 6 & 10 \\
\hline Total & 22 & 33 \\
\hline
\end{tabular}

Table 1. Workplaces chosen for the study.

a measurement approach based on long-term radon monitoring over periods of 6-12 months, using both passive and active radon devices simultaneously, has been adopted. The aim of this study was to find if this protocol, suitable to allow the evaluation of the average radon concentration during only the actual working hours, can be employed in this kind of workplaces using an affordable active device recently introduced on the market.

\section{Materials and methods}

Sampling. Four types of workplaces have been identified among those ones with public access (Table 1) and for which different radon levels are expected to occur during the working hours due to a likely increase of natural or mechanical ventilation. These workplaces were mainly located in Municipalities classified as radon prone areas in Tuscany and preferentially among those resulted to have an average annual radon concentration higher than $150 \mathrm{~Bq} \mathrm{~m}^{-3}$ in the framework of a radon survey conducted in this region one decade ago.

For each workplace, rooms to be monitored were chosen among those having ventilation conditions representative of nearly all the rooms. In presence of rooms with different ventilation regimes, if possible, another active device has been deployed.

Most of the rooms ( $85 \%$ of them) were located at the ground floor or basement, i.e., at floors where radon concentration measurements are mandatory for workplaces within radon priority areas of the EU Member States, according to the current European Directive ${ }^{2}$.

Experimental protocol. In each room of the chosen workplaces, annual radon concentration measurements were performed using passive radon devices over two consecutive 6-months periods. With the aim to estimate radon exposure during working hours, active radon detectors were simultaneously deployed with passive radon devices during the first 6-month period.

Although a 6-month period (occurring mainly in winter and spring seasons) was considered adequate to estimate the impact of air exchange rate occurring during working hours, in a sample of 11 rooms, active radon detectors were exposed also during the second 6-month period. These rooms were prevalently chosen among those resulted to have average radon concentration during the first 6-month period higher than $150 \mathrm{~Bq} \mathrm{~m}^{-3}$, according to the results of active radon detectors.

The first 6-month period started in winter (between December 2018 and February 2019) and ended in summer (between June and August 2019). The annual exposure ended between December 2019 and February 2020.

For each room and each exposure period, for the active radon device an acquisition time of $1 \mathrm{~h}$ was chosen, which allow to have an adequate time-resolution for estimating the radon concentration during the working hours ${ }^{10}$.

Radon devices. Passive devices were alpha track detectors (ATD), having CR-39 (TASL) as sensitive material, enclosed in a small diffusion chamber. Etching was performed in $6.25 \mathrm{NaOH}$ solution for 60 min and track counting was performed with a fully automated image analysis system (TASLIMAGE).

Measurements have been conducted in the Radioactivity laboratory of ARPA Toscana which was accredited on the basis of ISO/IEC $17025^{11}$.

As active devices, continuous monitors based on the electrostatic collection of the radon daughter emitting alpha particles on a silicon detector (model TSR 4 M produced by TESLA, Czech Republic). These devices allow to detect radon concentration every hour and they have a nominal sensitivity of about 25 counts per hour (cph) at a mean radon concentration of $100 \mathrm{~Bq} \mathrm{~m}^{-3}$. Therefore, they have an uncertainty of about $12 \%$ at $300 \mathrm{~Bq} \mathrm{~m}^{-3}$ due to the random Poisson component. The minimum detectable activity concentration is about $100 \mathrm{~Bq} \mathrm{~m}^{-3}$ for 1 - $h$ measurements.

These devices are also dependent on internal temperature and humidity which affect the electrostatic collection of the charged radon daughters on the detectors. Therefore, both these climatic parameters have been detected by the instrument and the sensitivity corrected accordingly.

The calibration of these devices has been performed by the means of an ad hoc intercomparison in our lab using professional AlphaGUARD as reference monitors.

\section{Results}

Intercomparison between AlphaGUARD and active monitors used for the study. Before the starting of the survey, all the active radon devices were deployed along with a professional radon monitor (AlphaGUARD PQ2000PRO) in order to evaluate their accuracy and their time response. This intercomparison was 


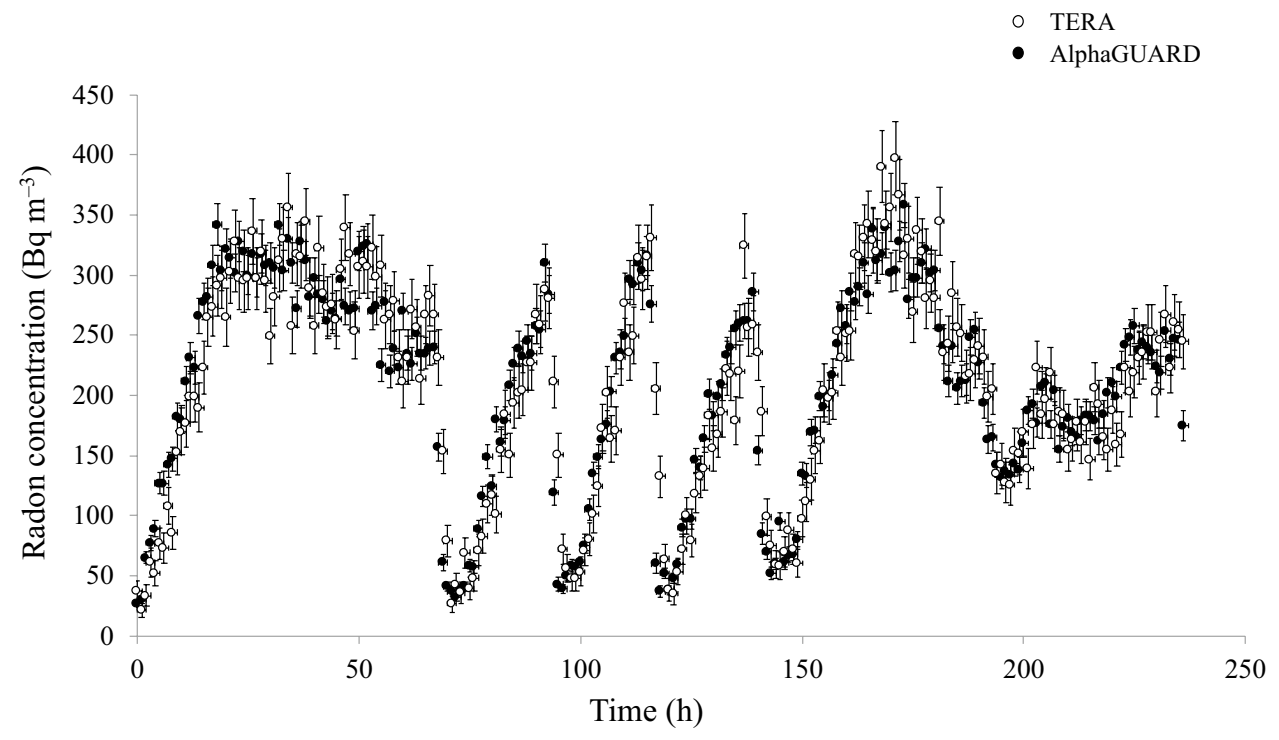

Figure 1. Intercomparison between AlphaGUARD PQ2000PRO (in diffusion mode) and TERA TSR $4 \mathrm{M}$ active device exposed in a room for about 10 days. An acquisition time of $1 \mathrm{~h}$ was chosen for both the instruments. The uncertainties reported in the graph have a coverage factor k equal to 1.

performed in an office room having an average radon level of about $200 \mathrm{~Bq} \mathrm{~m}^{-3}$, but normally experiencing daynight radon concentration variation, over a period of about 10 days.

It was found that on average the calibration factor of these probes was $50 \%$ lower than that of the AlphaGUARD. Instead, the time response of these probes resulted to be as good as that of the professional monitor (see Fig. 1).

Notably, it is a good time-response of the active devices that allow to correctly evaluate any difference of radon levels during working hours as compared with the remaining ones. Therefore, the lack of accuracy was considered not important considering the aim of this study. However, all the calibration factors of the TERA probes were corrected taking into account the average radon concentration measured by the AlphaGUARD monitor, and the following analyses have been performed using the corrected calibration factors.

Comparison between active and passive devices. For each monitored room, average radon concentration results were reported in Table 2 for each exposure period. In this table, both results of the passive devices $\left(\mathrm{RnC}_{\mathrm{CR}-39}\right)$ and active devices are included. For the active devices, radon levels were integrated over all the days $\left(\mathrm{RnC}_{\mathrm{H} 24}\right)$ and over the working hours $\left(\mathrm{RnC}_{\mathrm{WH}}\right)$ and the ratios of these values $\left(\mathrm{R}_{\mathrm{WH}} / \mathrm{h} 24\right)$ are also reported.

As shown in Table 2, for each type of workplaces there is at least one room with annual average radon concentrations higher than $300 \mathrm{~Bq} \mathrm{~m}^{-3}$, the maximum reference level for a European Member State according to the $2013 / 59 /$ Euratom Directive ${ }^{2}$. This was expected considering that in the sampling strategy workplaces were preferably chosen in Municipalities classified as radon prone areas in 2012.

Results of the average radon measurements performed using active radon devices $\left(\mathrm{RnC}_{\mathrm{H} 24}\right.$ in Table 2$)$ showed enough agreement with those performed using passive radon devices $\left(\mathrm{RnC}_{\mathrm{CR} 39}\right.$ in Table 2$)$. Their differences are mostly lower than $30 \%$ (the area between the two dashed lines in Fig. 2) especially for rooms having a mean radon level higher than $300 \mathrm{~Bq} \mathrm{~m}^{-3}$. In particular, for the first 6-month period, the median of the difference between active and passive devices is equal to $7 \%$ (range: $-70 \%$ to $70 \%$ ), but for radon level higher than $300 \mathrm{~Bq} \mathrm{~m}^{-3}$, the median is $4 \%$ (range: $-40 \%$ to $30 \%$ ).

Regarding passive devices, factors that might have had an impact on the increase of uncertainties could be the ageing and fading ${ }^{12,13}$ as well as the presence of thoron ${ }^{14}$ and, for very high radon level, the tracks overlapping ${ }^{15}$. Regarding active devices, besides thoron ${ }^{16}$, another possible influencing factor on their response could be a not correct characterization as a function of climatic conditions since the used monitor are highly dependent on temperature and humidity ${ }^{17}$.

These results-although not as good as those of metrological type carried out in a radon chamber-are similar in terms of accuracy to those performed in the framework of intercomparison under field conditions ${ }^{18,19}$.

Radon concentration during working hours $\left(\mathrm{RnC}_{\mathrm{WH}}\right)$ versus during the total time $\left(\mathrm{RnC}_{\mathrm{H} 24}\right)$. The average radon level over the working hours $\left(\mathrm{RnC}_{\mathrm{WH}}\right)$ generally resulted lower than the average over all the hours $\left(\mathrm{RnC}_{\mathrm{H} 24}\right)$ : this difference is always not higher than $50 \%$ and in most cases is not higher than $20 \%$ for each type of workplaces (see Table 2 and Fig. 3).

In particular, for the first 6-month period of exposure, the average $\mathrm{R}_{\mathrm{WH}} / \mathrm{h} 24$ is 0.8 (range: $0.5-1.0$ ). For the 11 rooms with also the second 6-month of exposure, the values of $\mathrm{R}_{\mathrm{WH}} / \mathrm{h} 24$ are even (slightly) higher (see Table 2) being the average equal to 0.9 (range: $0.8-1.0$ ). 


\begin{tabular}{|c|c|c|c|c|c|c|c|c|c|c|c|c|c|c|c|c|c|}
\hline \multirow[b]{2}{*}{$\begin{array}{l}\text { Type of } \\
\text { workplace }\end{array}$} & \multirow[b]{2}{*}{ Building } & \multirow[b]{2}{*}{ Room } & \multirow[b]{2}{*}{$\begin{array}{l}\text { Room } \\
\text { type }\end{array}$} & \multirow[b]{2}{*}{ Floor } & \multirow[b]{2}{*}{$\begin{array}{l}\text { Access } \\
\text { to the } \\
\text { public }\end{array}$} & \multicolumn{4}{|c|}{ 1st 6-month period } & \multicolumn{4}{|c|}{ 2nd 6-month period } & \multicolumn{4}{|c|}{ 12-month period } \\
\hline & & & & & & \begin{tabular}{|l|}
$\mathrm{RnC}_{\mathrm{CR}-39}$ \\
$\left(\mathbf{B q ~ m}^{-3}\right)$
\end{tabular} & $\begin{array}{l}\mathrm{RnC}_{\mathrm{H} 24} \\
(\mathbf{B q} \\
\left.\mathrm{m}^{-3}\right) \\
\end{array}$ & \begin{tabular}{|l|}
$\mathrm{RnC}_{\mathrm{WH}}$ \\
$(\mathbf{B q}$ \\
$\left.\mathbf{m}^{-3}\right)$ \\
\end{tabular} & $\mathbf{R}_{\mathrm{WH}} / \mathbf{h 2 4}$ & $\begin{array}{l}\operatorname{RnC}_{\text {CR-39 }} \\
\left(\mathbf{B q ~ m}^{-3}\right)\end{array}$ & \begin{tabular}{|l|}
$\mathrm{RnC}_{\mathrm{H} 24}$ \\
$(\mathbf{B q}$ \\
$\left.\mathrm{m}^{-3}\right)$ \\
\end{tabular} & $\begin{array}{l}\mathrm{RnC}_{\mathrm{WH}} \\
(\mathbf{B q} \\
\left.\mathrm{m}^{-3}\right)\end{array}$ & $\mathbf{R}_{\mathrm{WH}} / \mathbf{h} 24$ & $\begin{array}{l}\mathrm{RnC}_{\mathrm{CR}-39} \\
\left(\mathbf{B q ~ m}^{-3}\right) \\
\end{array}$ & \begin{tabular}{|l|}
$\mathrm{RnC}_{\mathrm{H} 24}$ \\
$(\mathbf{B q}$ \\
$\left.\mathrm{m}^{-3}\right)$ \\
\end{tabular} & $\begin{array}{l}\mathrm{RnC}_{\mathrm{WH}} \\
(\mathbf{B q} \\
\left.\mathrm{m}^{-3}\right)\end{array}$ & $\mathbf{R}_{\mathrm{WH}} / \mathrm{h}_{24}$ \\
\hline \multirow{8}{*}{$\begin{array}{l}\text { Postal } \\
\text { office }\end{array}$} & 1 & 1 & Office & 0 & & 28 & 38 & 29 & 0.8 & 40 & & & & 34 & & & \\
\hline & 2 & 1 & Office & 0 & & 17 & 12 & 9 & 0.7 & 17 & & & & 17 & & & \\
\hline & 3 & 1 & \begin{tabular}{|l} 
Coun- \\
ter \\
room
\end{tabular} & 1 & Yes & 205 & 167 & 144 & 0.9 & 249 & 183 & 166 & 0.9 & 228 & 175 & 155 & 0.9 \\
\hline & 3 & 2 & Office & 1 & & 227 & 183 & 161 & 0.9 & 246 & & & & 237 & & & \\
\hline & 4 & 1 & \begin{tabular}{|l|}
$\begin{array}{l}\text { Storage } \\
\text { area }\end{array}$ \\
\end{tabular} & 0 & & 161 & 137 & 110 & 0.8 & 172 & & & & 167 & & & \\
\hline & 4 & 2 & \begin{tabular}{|l|} 
Coun- \\
ter \\
room
\end{tabular} & 0 & Yes & 171 & 168 & 137 & 0.8 & 204 & & & & 188 & & & \\
\hline & 5 & 1 & \begin{tabular}{|l|} 
Coun- \\
ter \\
room \\
\end{tabular} & 0 & Yes & 414 & 645 & 580 & 0.9 & 432 & 700 & 731 & 1.0 & 423 & 673 & 656 & 1.0 \\
\hline & 5 & 2 & Office & 0 & & 398 & 383 & 368 & 1.0 & 440 & & & & 420 & & & \\
\hline \multirow{10}{*}{ Restaurant } & 1 & 1 & \begin{tabular}{|l|}
$\begin{array}{l}\text { Restau- } \\
\text { rant }\end{array}$ \\
\end{tabular} & 0 & Yes & 181 & 279 & 258 & 0.9 & & & & & & & & \\
\hline & 2 & 1 & Kitchen & 0 & & 33 & 45 & 38 & 0.8 & 43 & & & & 38 & & & \\
\hline & 2 & 2 & \begin{tabular}{|l|}
$\begin{array}{l}\text { Restau- } \\
\text { rant }\end{array}$ \\
\end{tabular} & 0 & Yes & 64 & 57 & 52 & 0.9 & 72 & & & & 68 & & & \\
\hline & 3 & 1 & Kitchen & 0 & & 54 & 91 & 73 & \begin{tabular}{|l|}
0.8 \\
\end{tabular} & 78 & & & & 66 & & & \\
\hline & 3 & 2 & \begin{tabular}{|l|}
$\begin{array}{l}\text { Restau- } \\
\text { rant }\end{array}$ \\
\end{tabular} & 0 & Yes & 159 & 125 & 114 & 0.9 & 174 & & & & 167 & & & \\
\hline & 4 & 1 & Kitchen & -0.5 & & 67 & 78 & 65 & 0.8 & 76 & & & & 72 & & & \\
\hline & 4 & 2 & \begin{tabular}{|l|}
$\begin{array}{l}\text { Restau- } \\
\text { rant }\end{array}$ \\
\end{tabular} & -1 & Yes & 180 & 225 & 203 & 0.9 & 160 & 269 & 237 & 0.9 & 170 & 248 & 220 & 0.9 \\
\hline & 5 & 1 & Kitchen & 1 & & 3490 & 4621 & 3114 & \begin{tabular}{|l|}
0.7 \\
\end{tabular} & 4209 & 5744 & 4695 & 0.8 & 3864 & 5205 & 3937 & \begin{tabular}{|l|}
0.8 \\
\end{tabular} \\
\hline & 5 & 2 & \begin{tabular}{|l|}
$\begin{array}{l}\text { Restau- } \\
\text { rant }\end{array}$ \\
\end{tabular} & 0 & Yes & 1159 & 1105 & 1015 & 0.9 & 1446 & 1716 & 1656 & 1.0 & 1308 & 1423 & 1349 & 0.9 \\
\hline & 6 & 1 & \begin{tabular}{|l|}
$\begin{array}{l}\text { Restau- } \\
\text { rant }\end{array}$ \\
\end{tabular} & 0 & Yes & 246 & 134 & 132 & 1.0 & 204 & 131 & 132 & 1.0 & 225 & 132 & 132 & 1.0 \\
\hline \multirow{5}{*}{ Shop } & 1 & 1 & \begin{tabular}{|l|}
$\begin{array}{l}\text { Sales } \\
\text { area }\end{array}$ \\
\end{tabular} & 0 & Yes & 382 & 411 & 221 & 0.5 & 284 & & & & 332 & & & \\
\hline & 2 & 1 & \begin{tabular}{|l|}
$\begin{array}{l}\text { Sales } \\
\text { area }\end{array}$ \\
\end{tabular} & 0 & Yes & 201 & 61 & 40 & 0.7 & 168 & & & & 184 & & & \\
\hline & 3 & 1 & \begin{tabular}{|l|}
$\begin{array}{l}\text { Sales } \\
\text { area }\end{array}$ \\
\end{tabular} & 0 & Yes & 173 & 153 & 129 & 0.8 & 194 & & & & 184 & & & \\
\hline & 4 & 1 & $\begin{array}{l}\begin{array}{l}\text { Sales } \\
\text { area }\end{array} \\
\end{array}$ & 0 & Yes & 215 & 114 & 84 & 0.7 & 254 & & & & 235 & & & \\
\hline & 5 & 1 & \begin{tabular}{|l|}
$\begin{array}{l}\text { Sales } \\
\text { area }\end{array}$ \\
\end{tabular} & 0 & Yes & 117 & 82 & 70 & 0.9 & 366 & & & & 244 & & & \\
\hline \multirow{10}{*}{$\begin{array}{l}\text { Municipal } \\
\text { office }\end{array}$} & 1 & 1 & Office & 1 & Yes & 314 & 278 & 210 & 0.8 & 308 & & & & 311 & & & \\
\hline & 1 & 2 & $\begin{array}{l}\text { Police } \\
\text { office }\end{array}$ & 1 & Yes & 326 & 314 & 197 & 0.6 & 383 & & & & 355 & & & \\
\hline & 2 & 1 & $\begin{array}{l}\text { Police } \\
\text { office }\end{array}$ & 0 & Yes & 420 & 376 & 291 & 0.8 & 477 & 567 & 462 & 0.8 & 449 & 473 & 377 & 0.8 \\
\hline & 2 & 2 & \begin{tabular}{|l|}
$\begin{array}{l}\text { Archive } \\
\text { room }\end{array}$ \\
\end{tabular} & 0 & & 566 & 526 & 418 & 0.8 & 619 & 682 & 568 & 0.8 & 593 & 605 & 494 & 0.8 \\
\hline & 3 & 1 & \begin{tabular}{|l|}
$\begin{array}{l}\text { Archive } \\
\text { room }\end{array}$ \\
\end{tabular} & -0.5 & & 90 & 92 & 74 & 0.8 & 86 & & & & 88 & & & \\
\hline & 3 & 2 & Office & 0 & & 202 & 163 & 94 & 0.6 & 204 & & & & 203 & & & \\
\hline & 4 & 1 & Office & 0 & & 458 & 446 & 318 & 0.7 & 636 & 566 & 482 & 0.9 & 548 & 507 & 401 & 0.8 \\
\hline & 5 & 1 & Office & 0 & & 384 & 279 & 247 & \begin{tabular}{|l|}
0.9 \\
\end{tabular} & 415 & 373 & 336 & \begin{tabular}{|l|}
0.9 \\
\end{tabular} & 400 & 327 & 292 & 0.9 \\
\hline & 5 & 2 & Office & 0 & Yes & 206 & 134 & 101 & 0.8 & 230 & 236 & 186 & 0.8 & 218 & 186 & 144 & 0.8 \\
\hline & 6 & 1 & Office & 0 & Yes & 299 & 298 & 268 & 0.9 & 299 & & & & 299 & & & \\
\hline
\end{tabular}

Table 2. Results of the average radon concentration measurements (over two 6-month periods and over 1 year) performed using passive radon devices $\left(\mathrm{RnC}_{\mathrm{CR}-39}\right)$ and active ones integrating radon levels over the all the days $\left(\mathrm{RnC}_{\mathrm{H} 24}\right)$ and over the working hours $\left(\mathrm{RnC}_{\mathrm{WH}}\right)$. The uncertainties for $\mathrm{RnC}_{\mathrm{H} 24}$ and $\mathrm{RnC}_{\mathrm{WH}}$ (not reported in the table) are of the order of $10 \%(\mathrm{k}=1)$. Legends for floor: $0=$ ground floor; $-0.5=$ basement; $1=$ first floor. 


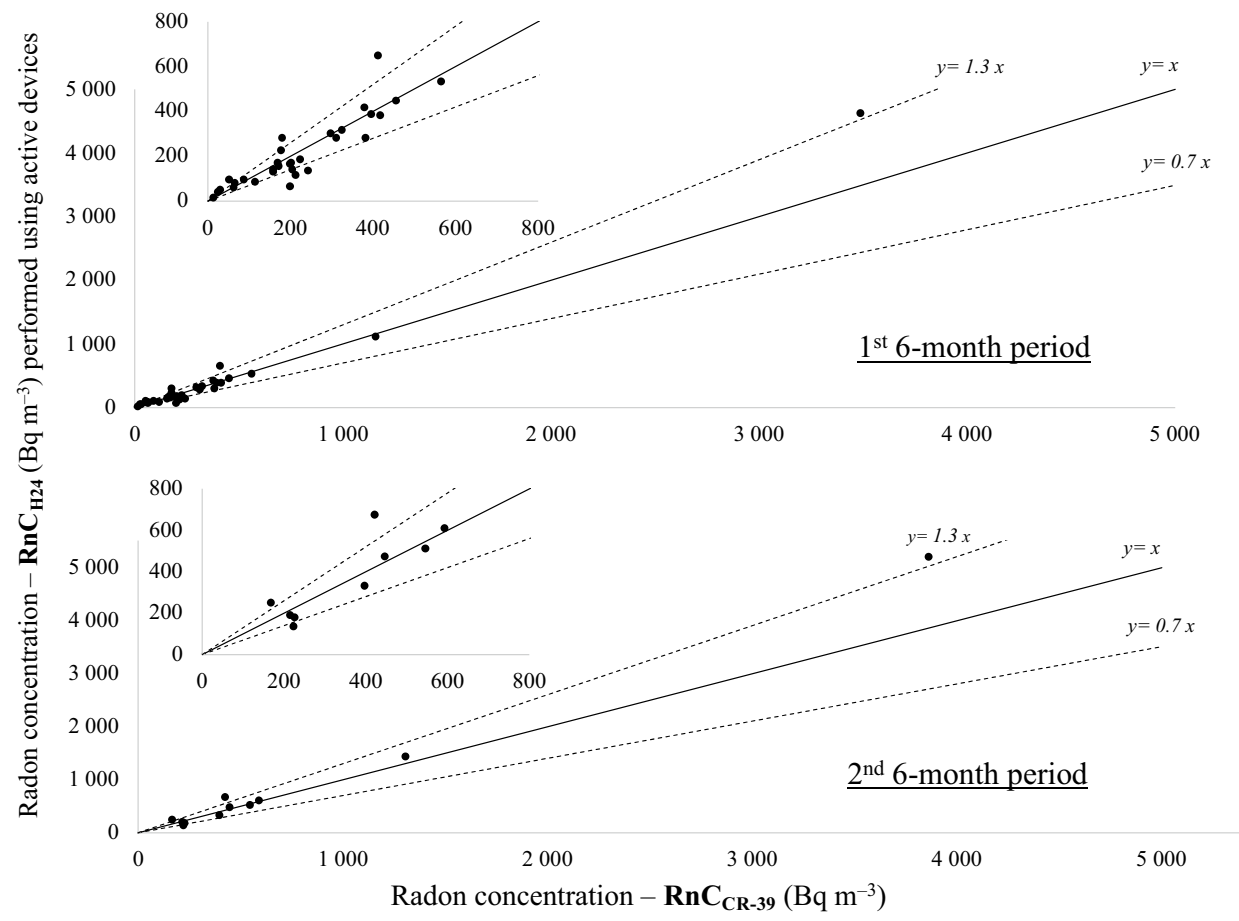

Figure 2. Comparison between average radon concentrations results measured using passive radon devices (x-axes) and active devices (y-axes) both for first (above) and the second 6-month period of exposure (below). The smaller plots are a zoom in the range $0-800 \mathrm{~Bq} \mathrm{~m}^{-3}$.
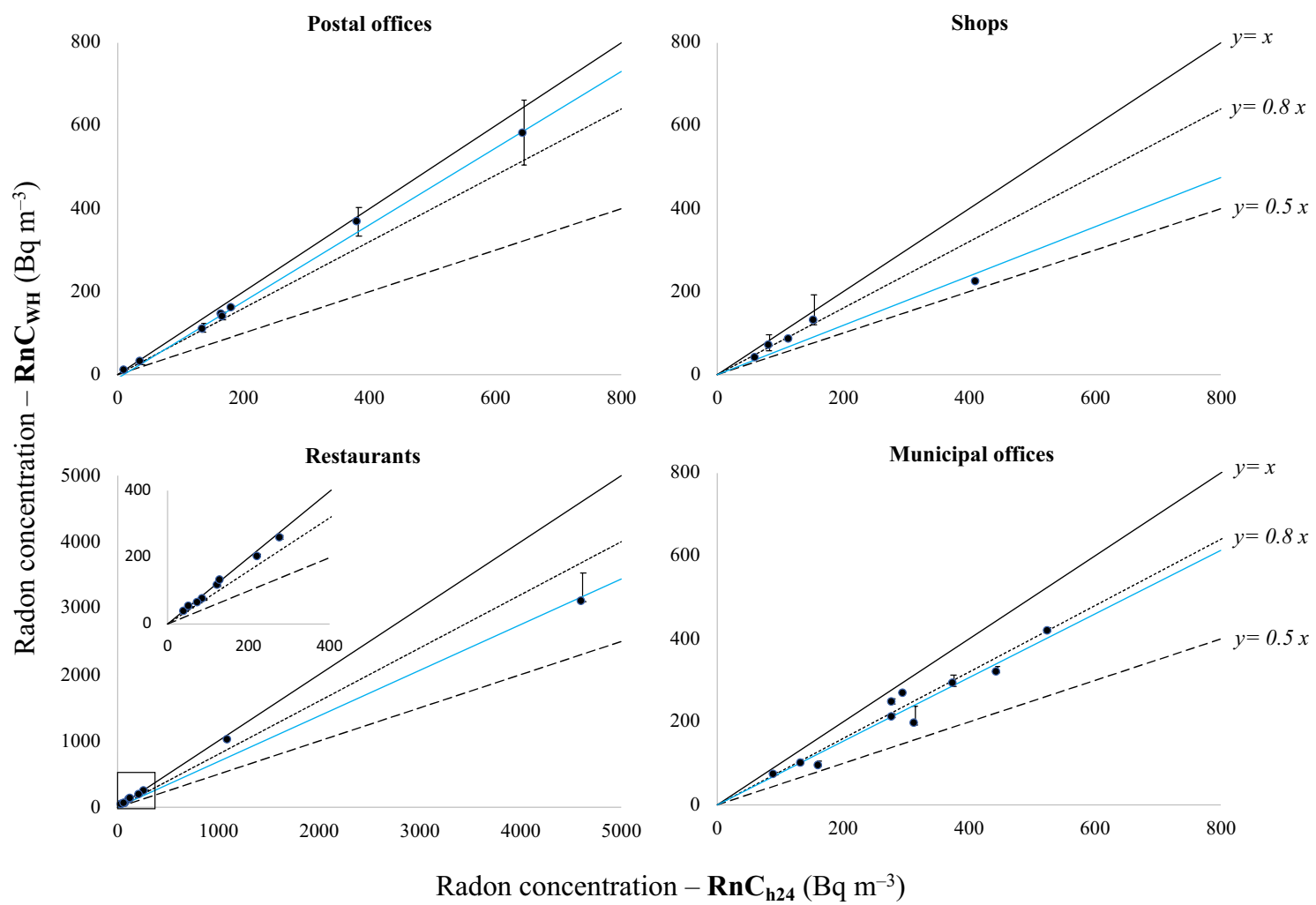

Figure 3. Comparison between average radon concentrations, over the all the days and hours $\left(\mathrm{RnC}_{\mathrm{H} 24}\right)$ and over the working hours $\left(\mathrm{RnC}_{\mathrm{WH}}\right)$ only, for the first 6-month period of exposure. The full lines represent the bisecting lines. The dotted and dashed lines represent lines with slopes of 0.8 and 0.5 , respectively. The best fit lines are in blue. As y error bars are reported the maximum differences with $\mathrm{RnC}_{\mathrm{WH}}$ (reported in Table 3) estimated varying of $1-2 \mathrm{~h}$ the actual working hours. The smaller plot in the restaurants box is a zoom in the range $0-400 \mathrm{~Bq} \mathrm{~m}^{-3}$. 


\begin{tabular}{|c|c|c|c|c|c|c|c|c|c|c|c|}
\hline \multirow[b]{3}{*}{ Type of workplace } & \multirow[b]{3}{*}{ Building } & \multirow[b]{3}{*}{ Room } & \multirow{3}{*}{$\begin{array}{l}\mathrm{RnC}_{\mathrm{WH}} \\
\left(\mathrm{Bq} \mathrm{m}^{-3}\right)\end{array}$} & \multicolumn{8}{|c|}{ Difference with $\mathrm{RnC}_{\mathrm{WH}}$ of } \\
\hline & & & & \multicolumn{2}{|c|}{$\mathrm{RnC}_{\mathrm{WH}}(-2 \mathrm{~h})$} & \multicolumn{2}{|c|}{$\mathrm{RnC}_{\mathrm{WH}}(-1 \mathrm{~h})$} & \multicolumn{2}{|c|}{$\mathrm{RnC}_{\mathrm{WH}}(+1 \mathrm{~h})$} & \multicolumn{2}{|c|}{$\mathrm{RnC}_{\mathrm{WH}}(+2 \mathrm{~h})$} \\
\hline & & & & $\left(\mathrm{Bq} \mathrm{m}^{-3}\right)$ & $\%$ & $\left(\mathrm{~Bq} \mathrm{~m}^{-3}\right)$ & $\%$ & $\left(\mathrm{~Bq} \mathrm{~m}^{-3}\right)$ & $\%$ & $\left(\mathrm{~Bq} \mathrm{~m}^{-3}\right)$ & $\%$ \\
\hline \multirow{8}{*}{ Postal office } & 1 & 1 & 29 & 5 & 16 & 2 & 8 & -2 & -8 & -4 & -12 \\
\hline & 2 & 1 & 9 & 2 & 22 & 1 & 14 & -1 & -9 & -1 & -12 \\
\hline & 3 & 1 & 144 & 3 & 2 & 2 & 1 & -1 & -1 & -2 & -1 \\
\hline & 3 & 2 & 161 & 3 & 2 & 1 & 1 & -1 & -1 & -3 & -2 \\
\hline & 4 & 1 & 110 & 13 & 11 & 6 & 5 & -5 & -4 & -7 & -6 \\
\hline & 4 & 2 & 137 & 14 & 10 & 6 & 5 & -4 & -3 & -5 & -4 \\
\hline & 5 & 1 & 580 & 81 & 14 & 41 & 7 & -41 & -7 & -75 & -13 \\
\hline & 5 & 2 & 368 & 34 & 9 & 18 & 5 & -17 & -5 & -33 & -9 \\
\hline \multirow{10}{*}{ Restaurant } & 1 & 1 & 258 & 7 & 3 & 2 & 1 & -3 & -1 & -1 & 0 \\
\hline & 2 & 1 & 38 & -1 & -3 & -1 & -2 & -1 & -1 & 1 & 2 \\
\hline & 2 & 2 & 52 & -1 & -3 & -1 & -2 & 0 & 0 & 2 & 4 \\
\hline & 3 & 1 & 73 & -2 & -3 & -1 & -2 & 0 & 0 & 3 & 4 \\
\hline & 3 & 2 & 114 & -4 & -3 & -2 & -2 & 1 & 1 & 2 & 2 \\
\hline & 4 & 1 & 65 & -1 & -2 & -1 & -2 & 2 & 2 & 6 & 9 \\
\hline & 4 & 2 & 203 & 6 & 3 & 3 & 1 & 0 & 0 & 6 & 3 \\
\hline & 5 & 1 & 3114 & 414 & 13 & 123 & 4 & 11 & 0 & 274 & 9 \\
\hline & 5 & 2 & 1015 & 48 & 5 & 20 & 2 & -9 & -1 & 3 & 0 \\
\hline & 6 & 1 & 132 & 3 & 2 & 2 & 1 & 0 & 0 & -2 & -2 \\
\hline \multirow{5}{*}{ Shop } & 1 & 1 & 221 & 64 & 29 & 31 & 14 & -10 & -4 & 10 & 5 \\
\hline & 2 & 1 & 40 & 4 & 10 & 1 & 3 & 1 & 2 & 4 & 10 \\
\hline & 3 & 1 & 129 & 27 & 21 & 12 & 10 & -9 & -7 & -12 & -10 \\
\hline & 4 & 1 & 84 & 28 & 33 & 14 & 17 & -12 & -14 & -16 & -19 \\
\hline & 5 & 1 & 70 & 7 & 10 & 4 & 6 & -4 & -5 & -5 & -7 \\
\hline \multirow{10}{*}{ Municipal office } & 1 & 1 & 210 & 8 & 4 & 6 & 3 & 0 & 0 & 6 & 3 \\
\hline & 1 & 2 & 197 & 41 & 21 & 17 & 9 & -6 & -3 & -1 & 0 \\
\hline & 2 & 1 & 291 & 21 & 7 & 10 & 3 & -4 & -2 & -5 & -2 \\
\hline & 2 & 2 & 418 & 9 & 2 & 3 & 1 & 2 & 0 & 8 & 2 \\
\hline & 3 & 1 & 74 & -1 & -1 & 0 & 0 & 2 & 2 & 4 & 5 \\
\hline & 3 & 2 & 94 & 10 & 11 & 4 & 5 & 1 & 1 & 8 & 8 \\
\hline & 4 & 1 & 318 & 17 & 5 & 8 & 2 & 1 & 0 & 9 & 3 \\
\hline & 5 & 1 & 247 & 9 & 4 & 5 & 2 & -3 & -1 & -2 & -1 \\
\hline & 5 & 2 & 101 & 8 & 8 & 7 & 7 & -4 & -4 & -4 & -4 \\
\hline & 6 & 1 & 268 & 26 & 10 & 11 & 4 & -10 & -4 & -18 & -7 \\
\hline
\end{tabular}

Table 3. Sensitivity analysis: differences with the average radon levels during working hours $\left(\mathrm{RnC}_{\mathrm{WH}}\right)$ as reported in Table 1 and average radon levels during working hours shifting the opening hours of 1 and $2 \mathrm{~h}$ (both back and forth).

Moreover, on average there are no significant differences, in terms of $\mathrm{R}_{\mathrm{WH}} / \mathrm{h} 24$, between rooms with access to the public and the remaining ones. Similarly, no differences are found between rooms with radon level higher and lower than $300 \mathrm{~Bq} \mathrm{~m}^{-3}$.

In order to find if these results could be affected by variation of the actual working hours, a sensitivity analysis was performed varying the working hours: for each room, opening (and closure) times were shifted of both 1 and $2 \mathrm{~h}$ and the average radon concentration during the working hours $\left(\mathrm{RnC}_{\mathrm{WH}}\right)$ was calculated accordingly (see Table 3).

The results of this sensitivity analysis show that the impact of changing the working hours is generally nonsignificant. The $\mathrm{RnC}_{\mathrm{WH}}$ varies on average by $2 \%$ and at maximum by $33 \%$. For those rooms with average radon concentrations higher than $300 \mathrm{~Bq} \mathrm{~m}^{-3}$, the impact is even lower: $\mathrm{RnC}_{\mathrm{WH}}$ varies on average by $2 \%$ at maximum by $14 \%$.

This analysis confirms that, as compared to average results over all the time (including nights and weekends), radon reduction during working hours usually resulted not higher than $20 \%$ for the type of workplaces considered in this study. Results of the present study indicate that the effect of natural or mechanical ventilation during the working hours of the monitored workplaces cannot be considered as an effective mitigation measure, and in turn to avoid the implementation of remedial actions in case annual average radon concentration $\mathrm{RnC}_{\mathrm{H} 24}$ resulted to be higher than a reference level (RL). It is worth noting that some of these workplaces, having $\mathrm{RnC}_{\mathrm{H} 24}$ slightly higher than a reference level (RL), could have instead a $\mathrm{RnC}_{\mathrm{WH}}$ lower than $\mathrm{RL}$, even if close to it. In these cases, 


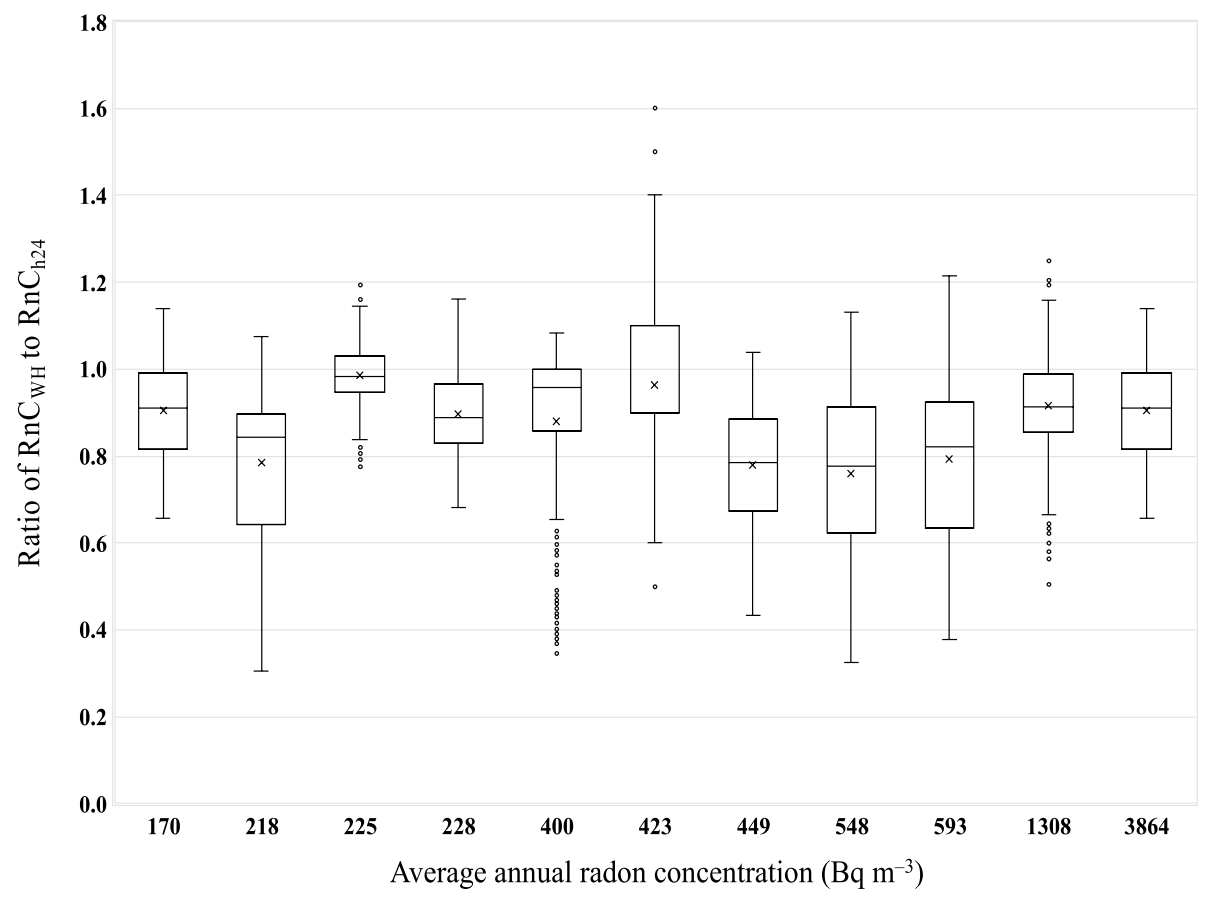

Figure 4. Box-plot of the ratio between $\mathrm{RnC}_{\mathrm{WH}}$ and $\mathrm{RnC}_{\mathrm{H} 24}$ estimated for each 7-day period of the year to the 11 rooms for which annual radon measurements with active devices were performed. On the $\mathrm{x}$-axis, the average annual radon concentrations for these 11 rooms are reported.

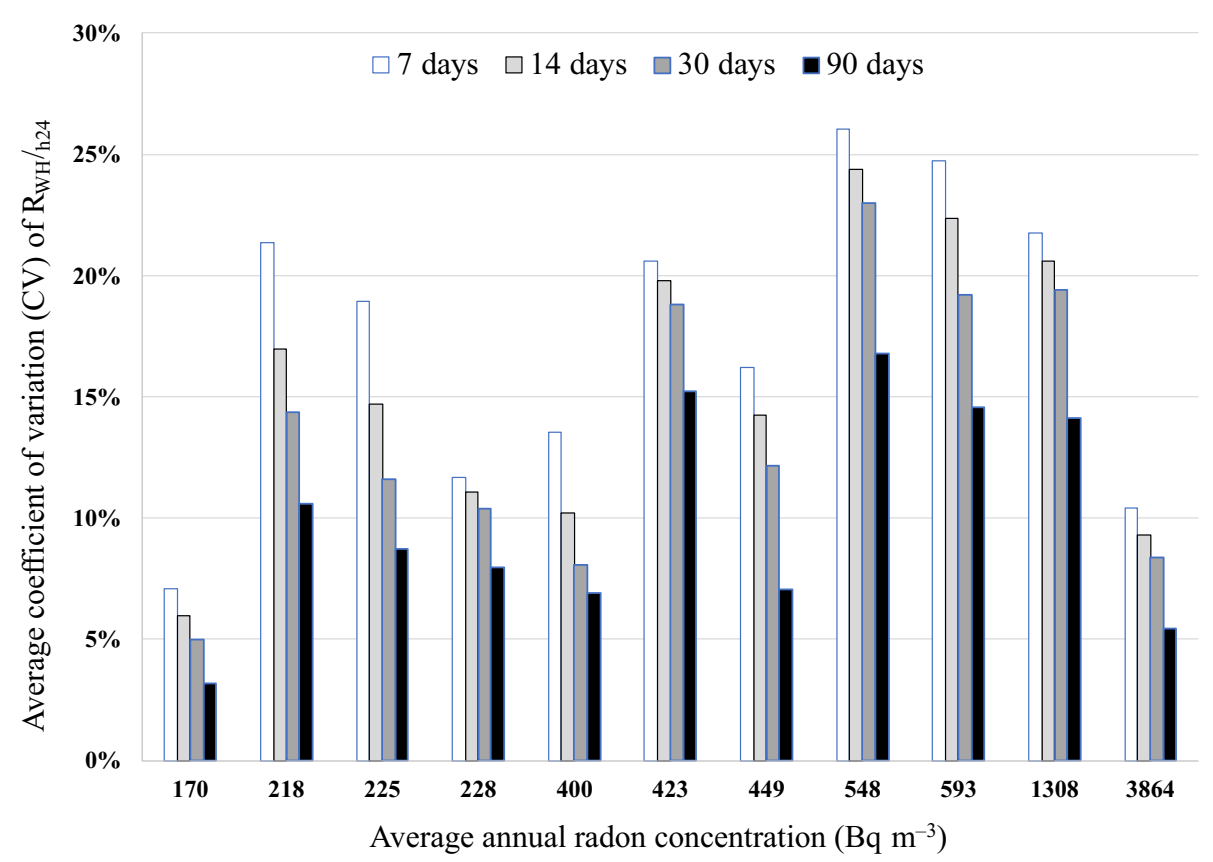

Figure 5. Average coefficient of variation of the ratio between $\mathrm{RnC}_{\mathrm{WH}}$ and $\mathrm{RnC}_{\mathrm{H} 24}\left(\mathrm{R}_{\mathrm{WH}} / \mathrm{h} 24\right)$ estimated for each 7-day, 14- day, 30-day, and 90-day period of the year for the 11 rooms for which annual radon measurements with active devices were performed. On the $\mathrm{x}$-axis, the average annual radon concentrations for these 11 rooms are reported. 
some measures aimed to reduce radon levels still needed to be performed, considering that the new concept of reference level require that optimization (and eventually radon exposure reduction) has to be implemented with priority above RL, but should also be implemented below it $^{20}$.

\section{Discussion}

Few studies were carried out to evaluate the effect of the ventilation during the working hours on radon levels, generally finding a much higher radon reduction during the working hours compared with the present study. In the UK, in a retail shop, a reduction of about $75 \%$ starting from an average radon concentration of about $1400 \mathrm{~Bq} \mathrm{~m}^{-3}$ was attributed to the turning on of an air-conditioning system ${ }^{21}$. A similar reduction during working hours (about 70\%) was found in two schools in Hungary, starting from about 500 and $300 \mathrm{~Bq} \mathrm{~m}^{-3} 22$.

In Nordic Countries a very high reduction (higher than 90\%) was found in two schools and public buildings. In particular, in Finland radon decrease from about $2000 \mathrm{~Bq} \mathrm{~m}^{-3}$ to about 100 and $20 \mathrm{~Bq} \mathrm{~m}^{-3}$, in a school and a day-care centre, respectively ${ }^{5}$. In Norway, in a seminar room of a university, average radon level decreased from about $5000 \mathrm{~Bq} \mathrm{~m}^{-3}$ to $130 \mathrm{~Bq} \mathrm{~m}^{-3}$, and, in an elementary school, from $300 \mathrm{~Bq} \mathrm{~m}^{-3}$ to $20 \mathrm{~Bq} \mathrm{~m}^{-3} 4$.

Notably, the above-mentioned studies were performed over periods not longer than 1-2 weeks, thus they were not able to evaluate the stability of the reduction during the working hours over longer periods, i.e., some months or a year, as it was done in the present study.

In fact, for each of the 11 rooms for which annual radon concentration measurements were performed using active devices, $\mathrm{RnC}_{\mathrm{WH}}$ and $\mathrm{RnC}_{\mathrm{H} 24}$ were calculated for each 7-day period of the year. As shown in Fig. 4, the interquartile ranges of $\mathrm{R}_{\mathrm{WH}} / \mathrm{h} 24$ are from about 0.6 to 1.1 , with a minimum value of about 0.3 , and maximum value of 1.6.

The choice of a random 7-day period over the year to estimate $\mathrm{R}_{\mathrm{WH}} / \mathrm{h} 24$ introduces an uncertainty-in terms of coefficient of variation (CV) of $\mathrm{R}_{\mathrm{WH}} /{ }_{\mathrm{h} 24}$ - of $17 \%$ on average (range: $7 \%-26 \%$ ). As shown in Fig. 5, the uncertainty obviously decreases (but not with the same rate for all the rooms) as the number of days chosen for the estimation of $\mathrm{R}_{\mathrm{WH}} / \mathrm{h} 24$ increases. In particular, the $\mathrm{CV}$ is $14 \%$ and $10 \%$ on average for a period of 30 and 90 days, respectively.

These results suggest to choose a period of several months in order to properly estimate using active radon monitors the impact of ventilation during working hours on the average annual radon concentration. However, further investigations are needed to confirm these results also on workplaces experiencing a radon reduction during the working hours much higher than that found in the present study.

Considering the costs of the active monitors recently introduced on the market, like those used for the present study, the choice to continuously measure radon concentration over a period of one year will probably be a good option for some types of workplaces. These types of active monitor could also be adopted as time-resolved personal measurement devices for exposed workers, i.e., in those workplaces where the exposure of workers is liable to exceed an effective dose of $6 \mathrm{mSv}$ per year or a corresponding time-integrated radon, as reported in art. 35.2 of 2013/59/Euratom Directive ${ }^{2}$. Up to now, in these cases (e.g., caves or mines), the evaluation of the effective radon exposure during working hours was generally performed using passive radon devices wore by the workers during the working hours and stored, when not in use, in low radon environments (Shahrokhi et al., 2017) or by passive radon monitors sensitive to radon only during the working hours ${ }^{23-25}$. However, time-resolved measurements performed using active monitors are in principle far more informative than the integrating measurement using passive devices, and the huge reduction of the costs the active devices will probably increase their use also as for personal radon exposure assessment.

Nevertheless, the results of the comparison of a type of active devices with passive ones carried out in the present study, suggest to perform further investigation in order to study their performances (accuracy, thoron interference, stability, and so on) both in radon chamber and under field conditions with exposure time of several months. Until then, it is however preferable to use, as in the present study, a passive device in combination with an active device having a good time-response: the first one to correctly evaluate the long-term average radon concentration; the second one to evaluate the ratio between radon levels during working hours as compared with the remaining ones and to correct the long-term average accordingly.

\section{Conclusions}

In the present study, active radon devices were used to evaluate the impact of the increased ventilation during working hours on the actual radon exposure of workers in 33 workplaces of different types (postal offices, shops, municipal offices, and restaurants).

The average difference between the average radon levels during working hours and during the whole days (including nights and weekends) resulted to be about $20 \%$, and ranged from 0 to $50 \%$. These results-equal also if the analysis is restricted to workplaces having average radon level higher than $300 \mathrm{~Bq} \mathrm{~m}^{-}$- suggest that natural or mechanical ventilation during the working hours of the monitored workplaces cannot be considered as an effective mitigation measure.

However, the costs of the active monitors as those used for the present study, as well as their good timeresponse characteristics, will probably lead to use them more frequently for workplaces where significant diurnal/ nocturnal variations in radon concentrations are likely.

Received: 13 May 2021; Accepted: 2 August 2021

Published online: 20 August 2021

\section{References}

1. World Health Organization. WHO Handbook on Indoor Radon: A Public Health Perspective (WHO, 2009).

2. European Commission. Council directive 2013/59/Euratom. Off. J. Eur. Union 57, L13 (2014). 
3. European Commission. Technical recommendations for monitoring individuals for occupational intakes of radionuclides Radiation Protection 188 https://doi.org/10.2833/393101 (2018).

4. Reisbacka, H. Radon measurements in conventional Finnish workplaces during measurement seasons 2005-2007. in Proceedings of the NSFS XV Conference in Ålesund Norway, 26-30 of May 2008 Vol. Strålevern 136 (2008).

5. Rydock, J. P., Næss-Rolstad, A. \& Brunsell, J. T. Diurnal variations in radon concentrations in a school and office: Implications for determining radon exposure in day-use buildings. Atmos. Environ. 35, 2921-2926 (2001).

6. Norwegian Radiation Protection Authority. Protocol for Radon Measurements in Schools. (2015).

7. Health Canada. Guide for Radon Measurements in Public Buildings. https://www.canada.ca/content/dam/hc-sc/migration/hc-sc/ ewh-semt/alt_formats/hecs-sesc/pdf/pubs/radiation/radon_building-edifices/27-15-1468-RadonMeasurements_PublicBuildingsEN13.pdf (2016).

8. European Commission. Radiation Protection. Radon in Workplaces-Implementing the Requirements in Council Directive 2013/59/ Euratom. https://doi.org/10.2833/957131 (2020).

9. Bucci, S. et al. Radon in workplaces: First results of an extensive survey and comparison with radon in homes. Radiat. Prot. Dosimetry 145, 202-205 (2011).

10. ICRU. Measurement and reporting of radon exposures. J. ICRU 12, 1-191 (2012).

11. ISO. ISO/IEC 17025: General requirements for the competence of testing and calibration laboratories. Int. Stand. https://doi.org/ 10.1109/IEEESTD.2015.7106438 (2017).

12. Venoso, G., Ampollini, M., Antignani, S., Carpentieri, C. \& Bochicchio, F. In-field evaluation of the impact of ageing and fading effects on annual radon concentration measurements for two different techniques. J. Radiol. Prot. 36, 922-933 (2016).

13. Hardcastle, G. D. \& Miles, J. C. H. Ageing and fading of alpha particle tracks in CR-39 exposed to air. Radiat. Prot. Dosimetry 67, 295-298 (1996).

14. Tokonami, S. et al. Influence of environmental thoron on radon measurements and related issues. In: AIP Conference Proceedings. American Institute of Physics, 145-148 (2008).

15. Ibrahimi, Z.-F., Howarth, C. B. \& Miles, J. C. H. Sources of error in etched-track radon measurements and a review of passive detectors using results from a series of radon intercomparisons. Radiat. Meas. 44, 750-754 (2009).

16. Beck, T. R., Buchröder, H. \& Schmidt, V. Performance tests for instruments measuring radon activity concentration. Appl. Radiat. Isot. 67, 876-880 (2009).

17. Roca, V. et al. The influence of environmental parameters in electrostatic cell radon monitor response. Appl. Radiat. Isot. 61, 243-247 (2004).

18. Berlier, F. et al. Main results of the second AIRP international radon-in-field intercomparison for passive measurement devices. Radiat. Meas. 128, 106177 (2019).

19. Rabago, D. et al. Intercomparison of indoor radon measurements under field conditions in the framework of metroradon european project. Int. J. Environ. Res. Public Health 17, 1780 (2020).

20. Bochicchio, F., Venoso, G., Antignani, S. \& Carpentieri, C. Radon reference levels and priority areas considering optimisation and avertable lung cancers. Radiat. Prot. Dosimetry 177, 87-90 (2017).

21. Marley, F. Utilisation of an air-conditioning system to control the levels of radon and radon progeny in a workplace environment. Radiat. Prot. Dosimetry 91, 403-407 (2000).

22. Kávási, N. et al. Difficulties in radon measurements at workplaces. Radiat. Meas. 41, 229-234 (2006).

23. Tommasino, L., Tommasino, M. C. \& Viola, P. Radon-film-badges by solid radiators to complement track detector-based radon monitors. Radiat. Meas. 44, 719-723 (2009).

24. Pressyanov, D., Dimitrov, D. \& Dimitrova, I. Passive radon monitors with part-time sensitivity to radon. Radiat. Meas. 118, 72-76 (2018).

25. Orlando, C. et al. A passive radon dosemeter suitable for workplaces. Radiat. Prot. Dosimetry 102, 163-168 (2002).

\section{Acknowledgements}

This work was carried out with the financial support of INAIL_BRIC ID 07 (2016). We would like to thank all the workers of the workplaces involved in this study for their collaboration and help.

\section{Author contributions}

F.B., S.B., C.C., F.L., A.I., R.T., and G.V. planned the study. A.I., G.P., and M.A. performed all the measurements. G.V., M.C., S.A., C.C., and C.D.C., analysed data. F.B., and S.B. supervised the design of the measurements. S.B., L.B., M.G., E.C. managed the contacts with the employers of the workplaces. G.V. prepared the first draft of the manuscript, which was reviewed by all the authors.

\section{Competing interests}

The authors declare no competing interests.

\section{Additional information \\ Correspondence and requests for materials should be addressed to G.V.}

Reprints and permissions information is available at www.nature.com/reprints.

Publisher's note Springer Nature remains neutral with regard to jurisdictional claims in published maps and institutional affiliations.

(c) (i) Open Access This article is licensed under a Creative Commons Attribution 4.0 International License, which permits use, sharing, adaptation, distribution and reproduction in any medium or format, as long as you give appropriate credit to the original author(s) and the source, provide a link to the Creative Commons licence, and indicate if changes were made. The images or other third party material in this article are included in the article's Creative Commons licence, unless indicated otherwise in a credit line to the material. If material is not included in the article's Creative Commons licence and your intended use is not permitted by statutory regulation or exceeds the permitted use, you will need to obtain permission directly from the copyright holder. To view a copy of this licence, visit http://creativecommons.org/licenses/by/4.0/.

(C) The Author(s) 2021 